Ciência Florestal, Santa Maria, v. 20, n. 3, p. 523-532 jul.-set., 2010

\title{
INFLUÊNCIA DO ÂNGULO DE PLANTIO SOBRE A BROTAÇÃO E O ENRAIZAMENTO DE ESTACAS DE Phyllanthus sellowianus (Klotzsch) Müll. Arg.
}

\author{
INFLUENCE OF PLANTING ANGLE ON THE SHOOTING AND ROOTING OF CUTTINGS OF \\ Phyllanthus sellowianus (Klotzsch) Müll. Arg.
}

Josita Soares Monteiro ${ }^{1}$ Michele Benetti Leite ${ }^{2}$ Charlote Wink ${ }^{3} \quad$ Miguel Antão Durlo ${ }^{4}$

RESUMO

A estabilização de encostas naturais ou artificiais de terrenos e margens de cursos de água é possível com a aplicação de técnicas propostas pela engenharia natural ou bioengenharia de solos, que utilizam a vegetação, sozinha ou combinada com materiais inertes. Para isso, a vegetação a ser empregada necessita preencher alguns requisitos relacionados a aspectos ecológicos, fitossociológicos e de reprodução. As técnicas de engenharia natural utilizam as plantas em diferentes posições em relação à horizontal. Por essa razão, o presente trabalho tem por objetivo avaliar os efeitos de diferentes ângulos de plantio de estacas de Phyllanthus sellowianus (Klotzsch) Müll. Arg. para a estabilização de taludes. Com isso, será possível sugerir a forma mais adequada para o plantio dessa espécie, ou seja, em quais práticas biotécnicas esta pode ser melhor utilizada. O experimento foi conduzido no Viveiro Florestal, na Universidade Federal de Santa Maria (UFSM), Santa Maria, RS, no período de agosto a novembro de 2007. Os tratamentos consistiram no plantio de estacas de Phyllanthus sellowianus (Klotzsch) Müll. Arg., em três ângulos diferentes $\left(10^{\circ}\right.$, $30^{\circ} \mathrm{e} 90^{\circ}$ ). As estacas foram coletadas na região central do estado do RS e confeccionadas com $30 \mathrm{~cm}$ de comprimento ( $\pm 1 \mathrm{~cm}$ de variação), com diâmetro médio de $1,9 \mathrm{~cm}$. Dois terços de sua base foram inseridos em substrato inerte (areia). O delineamento experimental foi o inteiramente casualizado, com trinta repetições (estacas) por tratamento. Após 90 dias foram analisados as seguintes características: sobrevivência das estacas, número, comprimento e diâmetro dos brotos e raízes primárias, além da massa seca das raízes e brotos. A espécie apresentou altos valores de sobrevivência, com tendência de maiores resultados em estacas plantadas em ângulos de $10^{\circ}$ e $90^{\circ}$. O plantio de estacas em ângulo de $90^{\circ}$ também proporcionou os maiores valores da soma de comprimento e da massa seca dos brotos, enquanto que o diâmetro e o número de brotos não apresentaram diferenças significativas entre os ângulos de plantio. $\mathrm{O}$ número, a soma do comprimento e a massa seca das raízes, tiveram valores significativamente maiores em estacas plantadas em ângulo de $90^{\circ}$. O diâmetro da raiz mais longa apresentou maior média em estacas plantadas em ângulo de $10^{\circ}$, enquanto que o valor médio do comprimento da raiz mais longa por estaca não mostrou diferença estatística entre os três ângulos de plantio.

Palavras-chave: propagação vegetativa; estaquia; engenharia natural.

\begin{abstract}
The stabilization of natural or artificial slopes of land and shores of water courses is possible with the application of some techniques, proposed by natural engineers and soil bioengineers, which use vegetation

1. Engenheira Florestal, MSc., Doutoranda pelo Programa de Pós-graduação em Engenharia Florestal, Centro de Ciências Rurais, Universidade Federal de Santa Maria, Rua Marechal Floriano Peixoto, 498, Ap. 402, Centro, CEP 97010-310, Santa Maria (RS). jositasm@yahoo.com.br

2. Engenheira Florestal, Av. Independência 702, Bairro Passo da Areia, CEP 97010-240, Santa Maria (RS). micheleleit@gmail.com

3. Engenheira Florestal, MSc., Doutoranda do Programa de Pós-graduação em Engenharia Florestal, Centro de Ciências Rurais, Universidade Federal de Santa Maria, Rua Dr. Pantaleão 127, Ap. 402, Centro, CEP 97010-180, Santa Maria (RS). charlotewink@yahoo.com.br

4. Engenheiro Florestal, Dr., Professor Associado do Departamento de Ciências Florestais, Centro de Ciências Rurais, Universidade Federal de Santa Maria, Av. Roraima 1000, CEP 97105-900, Santa Maria (RS). migueldurlo@smail.ufsm.br

Recebido para publicação em 14/01/2009 e aceito em 12/04/2010.
\end{abstract}


alone or in combination with inert materials. For this reason, the vegetation to be employed needs to meet some requirements related to ecological, phytosociological and reproduction aspects. Techniques of natural engineering use plants in different positions in relation to the horizontal line. Thus, this study aims to evaluate the effects of different planting angles of cuttings of Phyllanthus sellowianus (Klotzsch) Müll. Arg. on slope stabilization. With these results the most appropriate form of planting this species can be proposed, ie, in which biotechnical practices it can be best used. The experiment was carried out at the Forest Nursery, at the Federal University of Santa Maria (UFSM), Santa Maria, Rio Grande do Sul. The study was done from August to November of 2007. Treatments consisted of planting cuttings of Phyllanthus sellowianus (Klotzsch) Müll. Arg. at three different angles $\left(10^{\circ}, 30^{\circ}\right.$ and $\left.90^{\circ}\right)$. Cuttings were 30 $\mathrm{cm}$ long ( $\pm 1 \mathrm{~cm}$ of variation), with an average diameter of $1.9 \mathrm{~cm}$, and were collected in the central region of the state of RS. Two-thirds of their base were inserted into inert substrate (sand). The experimental design was completely randomized, with 30 repetitions (cuttings) for each treatment. After 90 days, the following features were analyzed: cutting survival, number, length and diameter of shoots and primary roots besides the dry mass of roots and shoots. The species had high values of survival, with a tendency for very positive results for stem cuttings planted at angles of $10^{\circ}$ and $90^{\circ}$. Planting at an angle of $90^{\circ}$ also provided the highest values of the sum of the length and dry mass of shoots, while the diameter and number of shoots showed no significant differences between the angles of planting. The number, the sum of the length and dry mass of roots were significantly higher in cuttings planted at a $90^{\circ}$ angle. The diameter of the longest root presented the highest average in cuttings planted at a $10^{\circ}$ angle, while the average length of the longest root per cutting was not statistically different between the three angles of planting.

Keywords: vegetative propagation; cuttings; soil bioengineering.

\section{INTRODUÇ̃̃O}

Um campo especial da ciência, composto por uma coletânea sistemática de conhecimentos sobre diversas características da vegetação, métodos e formas de intervenção em áreas degradadas, conhecido como engenharia natural ou bioengenharia de solos está sendo retomado e vem se desenvolvendo rapidamente.

A engenharia natural também conhecida como engenharia biotécnica ou bioengenharia valese de técnicas-biológicas nas quais plantas ou parte destas são usadas como material vivo de construção. Sozinhas, ou combinadas com materiais inertes, tais plantas devem proporcionar estabilidade às áreas em tratamento, como encostas naturais ou artificiais de terrenos e margens de cursos de água (SCHIECHTL e STERN, 1992).

As obras longitudinais (DURLO e SUTILI, 2005) preconizadas pela engenharia natural não alteram a declividade do leito, tendo por função reconstruir, proteger e estabilizar as margens. Tais efeitos podem ser alcançados pelo revestimento vegetal e/ou físico das margens. Muitas vezes, não é necessário o revestimento total das margens, mas apenas parte destas, especialmente junto à linha de água. Tais intervenções podem ser o simples rearranjo de pedras e de troncos passando pelo uso de cilindros inertes ou vivos, tranças vivas, esteiras vivas, plantio em banquetas ou semeadura de diversas plantas (DURLO e SUTILI, 2005).

Por tais razões, antes do planejamento e da execução de obras de engenharia natural na tentativa de estabilização de taludes é fundamental que se tenha o conhecimento de características biotécnicas da vegetação a ser utilizada. Dentre estas, Durlo e Sutili (2005) destacam: resistência à exposição parcial das raízes; resistência ao aterramento parcial; resistência ao apedrejamento (provindo de barrancas altas e declivosas); capacidade de brotar após quebra do ápice e danos à planta; crescimento rápido e sistema radicial que permita fixar o solo, pelo comprimento, volume e resistência das raízes.

Quando se maneja cursos de água, geralmente, trabalha-se com sítios extremos onde se faz necessário estabilizar, recuperar ou reabilitar áreas degradadas (DURLO e SUTILI, 2005). O material vegetal empregado precisa preencher alguns requisitos, dependentes de cada situação particular de uso, considerando-se os aspectos ecológicos e fitossociológicos, de reprodução e, fundamentalmente, de aptidão biotécnica (SCHIECHTL, 1973; DURLO, 2000).

Segundo Fachinello et al. (1994) os métodos de propagação de plantas são divididos em dois tipos: sexuada que se baseia no uso de sementes, e assexuada baseada no uso de estruturas vegetativas. Um dos métodos mais antigos de propagação vegetativa utilizado para o recobrimento de solos degradados é a estaquia (SCHIECHTL, 1973). 
A capacidade de uma estaca emitir raízes é afetada por fatores endógenos e pelas condições ambientais proporcionadas ao enraizamento. Os fatores internos são representados pela condição fisiológica da matriz, a idade da planta, o tipo de estaca, a época do ano, o potencial genético de enraizamento, a sanidade, o balanço hormonal e, a oxidação de compostos fenólicos, já os fatores externos compreendem a temperatura, a luz, a umidade, o substrato e o condicionamento (FACHINELLO et al., 1994). Dentre os fatores internos o balanço hormonal ganha destaque. Este é referência para muitos estudos envolvendo a propagação vegetativa de espécies por meio da estaquia.

A auxina é o primeiro hormônio de crescimento vegetal a ser considerado, ao qual se pode atribuir a capacidade de promover o alongamento de segmentos de caules, divisão celular, formação de raízes adventícias, além de outros fenômenos do desenvolvimento relacionados à ação do AIA (ácido indol-3-acético) (TAIZ e ZEIGER, 2004). As auxinas têm transporte unidirecional ou polar, ou seja, movem-se sobretudo da extremidade apical para a basal (transporte basípeto) (AWAD e CASTRO, 1983; RAVEN et al., 1996; TAIZ e ZEIGER, 2004). Esse gradiente longitudinal da auxina da parte aérea até a raiz afeta vários processos do desenvolvimento, incluindo o alongamento do caule, a dominância apical, a cicatrização de lesões e a senescência foliar (TAIZ e ZEIGER, 2004).

Com base no exposto, pode-se julgar que a propagação de espécies de forma vegetativa, por meio de estacas, terá a formação de raízes adventícias afetada por esse gradiente de auxinas existente ao longo da estaca. Florineth (2004) aconselha o plantio inclinado para conseguir uma melhor distribuição das raízes na porção enterrada das estacas.

Segundo Schiechtl (1973), foi demonstrado que os comprimentos das raízes aumentam, antes de tudo, em correspondência ao volume, ou seja, ao comprimento das estacas. No entanto, no caso de estacas colocadas verticalmente não se nota, consequentemente, uma diferença tão marcante entre os comprimentos de estacas, porque a rizocalina move-se em maior parte em direção basal e as raízes formam-se sobre a superfície cortada, também na presença de uma estaca de comprimento pequeno, a uma profundidade favorável, não mais exposta ao dessecamento. No caso de estacas colocadas na posição horizontal, desenvolve-se, no entanto, em volta da raiz principal um denso maço de raízes laterais robustas, as quais surgem no ponto mais baixo do local do corte, porém a estaca cria raízes também em outros pontos ao longo de todo o seu comprimento, que está recoberto de terra, de modo que a soma do comprimento das raízes resulta sensivelmente maior.

Várias técnicas recomendadas pela bioengenharia exigem que a vegetação ora seja utilizada na posição vertical, ora na posição horizontal ou ora formando diferentes ângulos com o terreno. Quando se usa estacas como forma de propagação vegetativa a fim de estabilizar taludes, é fundamental conhecer a capacidade de pega do material vegetal, quando plantado em diferentes posições. Para os cilindros vivos, por exemplo, os feixes de estacas são posicionados quase horizontalmente no terreno, enquanto nas esteiras vivas, os ramos são implantados em ângulos entre $30^{\circ}$ a $45^{\circ}$. Na trança viva, as estacas são usadas desde a posição paralela com a horizontal até ângulos de $45^{\circ}$, ao passo que nas banquetas, o plantio geralmente é feito em pequenos ângulos entre $10^{\circ}$ e $20^{\circ}$.

Phyllanthus sellowianus (Klotzsch) Müll. Arg. é espécie originária do sul do Brasil, Uruguai e nordeste da Argentina (CABRERA et al., 1965). Trata-se de um arbusto que vive à margem dos rios e arroios, invadindo as águas (CABRERA et al., 1965; LOMBARDO, 1964). Integrante da família Phyllanthaceae (SOUZA e LORENZI, 2005) é conhecida vulgarmente pelos nomes de sarandi e sarandi-branco (LOMBARDO, 1964). Conforme Sutili (2004) esta se reproduz muito bem vegetativamente, o que pode ser observado pela sua capacidade de pega e, sobretudo, por providenciar um grande número de raízes logo após o plantio (2 meses), revelando um enraizamento denso.

Portanto, este trabalho teve por objetivo avaliar a influência do ângulo de plantio da estaca em relação à horizontal sobre a brotação e o enraizamento de Phyllanthus sellowianus (Klotzsch) Müll. Arg., a fim de sugerir a forma mais adequada para o seu plantio e presumir em quais práticas biotécnicas esta pode ser melhor utilizada.

\section{MATERIAL E MÉTODOS}

\section{Coleta das estacas}

O material vegetal de Phyllanthus sellowianus (Klotzsch) Müll. Arg. foi coletado às 
margens do arroio Grande, no município de Santa Maria, no Rio Grande do Sul, situado na região fisiográfica da Depressão Central do Estado, localizado a $29^{\circ} 43^{\prime} \mathrm{S}$ e $53^{\circ} 43^{\prime} \mathrm{O}$. O clima da região é classificado como "Cfa 2", de acordo com o sistema de Köeppen, definido como subtropical. A precipitação anual atinge valores próximos a 1700 $\mathrm{mm}$, com chuvas bem distribuídas ao longo do ano. No entanto, pode ocorrer período de déficit hídrico nos meses de verão que normalmente são quentes e secos. O município de Santa Maria apresenta a temperatura média do mês mais quente em torno de $24,8^{\circ} \mathrm{C}$ (janeiro), a temperatura média do mês mais frio ao redor de $14,1^{\circ} \mathrm{C}$ (julho) e a média anual oscila próximo dos $19^{\circ} \mathrm{C}$ (MORENO, 1961).

Foram selecionadas plantas matrizes que aparentavam boas condições sanitárias, idades e características semelhantes. Os ramos foram coletados inteiros, levados ao Viveiro Florestal da UFSM, onde as estacas foram confeccionadas com a parte central do ramo e utilizadas imediatamente no experimento.

\section{Instalação e condução do experimento}

O experimento foi realizado no Viveiro Florestal, na Universidade Federal de Santa Maria (UFSM), Santa Maria, RS, no período de agosto a novembro de 2007.

As estacas foram confeccionadas com 30 $\mathrm{cm}$ de comprimento ( $\pm 1 \mathrm{~cm}$ de variação), com diâmetros variáveis de 1,0 a $2,9 \mathrm{~cm}$, tendo o diâmetro médio em torno de $1,9 \mathrm{~cm}$. Essa pequena variação diamétrica não foi considerada na instalação do experimento.

As estacas foram plantadas em areia, na profundidade de dois terços de seu comprimento total. Para isso, a areia foi acondicionada em uma caixa de madeira nas dimensões de 2,10 $\mathrm{m}$ x 4,50 $\mathrm{m}$ $\mathrm{x} 0,30 \mathrm{~m}$, colocada à sombra onde foram distribuídas as estacas. Havia outras espécies sendo testadas na caixa de madeira, no mesmo período. O fundo da caixa foi feito de chapa de compensado, o qual foi perfurado a cada $20 \mathrm{~cm}$, para evitar o acúmulo de água.

As estacas foram plantadas em três ângulos de plantio em relação ao substrato: $10,30 \mathrm{e} 90^{\circ}$. A fim de facilitar a acomodação das estacas nas diferentes inclinações, foram elaborados gabaritos, que serviram de apoio para a inserção das estacas nos diferentes ângulos de plantio.
Para manter as boas condições de umidade, o substrato recebeu regas periódicas, bem como foi coberto por uma fina camada de restos culturais.

$\mathrm{O}$ ataque de formigas foi evitado pelo uso de uma pasta, aplicada ao redor de toda caixa de madeira, formando um "cinto protetor". Dessa forma, produziu-se uma barreira mecânica, impedindo que as formigas alcançassem as plantas. O produto não é tóxico ao homem, às plantas tão pouco às formigas, como dito, este apenas funciona como uma barreira física à passagem destas.

A avaliação da brotação e do enraizamento foi realizada aos 90 dias após a implantação do experimento.

\section{Delineamento experimental}

O experimento foi conduzido no delineamento inteiramente casualizado, com trinta repetições por tratamento, cada estaca correspondeu a uma repetição, assim, teve-se trinta estacas por tratamento. A distribuição das repetições deu-se por meio de sorteio.

Foram testados três tratamentos correspondentes aos três ângulos diferentes de plantio 10,30 e $90^{\circ}$ em relação à horizontal.

As estacas (repetições) foram distribuídas em linhas dentro da caixa de areia. Essas linhas ficaram distantes da borda da caixa $0,15 \mathrm{~m}$. A distância entre as estacas na linha foi de $0,10 \mathrm{~m}$, e entre as linhas foi de $0,20 \mathrm{~m}$.

\section{Variáveis analisadas}

Foram observados e registrados os seguintes parâmetros: número de estacas brotadas, número, comprimento $(\mathrm{cm})$ e diâmetro $(\mathrm{mm})$ dos brotos primários de cada estaca e massa seca das brotações (g); número de estacas enraizadas, número e comprimento $(\mathrm{cm})$ das raízes primárias de cada estaca, diâmetro $(\mathrm{mm})$ da raiz mais longa de cada estaca e massa seca das raízes $(\mathrm{g})$.

Foram consideradas brotadas e enraizadas as estacas que apresentaram uma ou mais brotações e raízes vivas respectivamente no momento da observação. Para a medição do comprimento de brotos e raízes primários, utilizou-se uma simples régua graduada em milímetros, e para o diâmetro destas, valeu-se de um paquímetro analógico.

Como brotos primários e raízes primárias foram considerados os que tinham origem diretamente da estaca. Não foram medidos os

Ci. Fl., v. 20, n. 3, jul.-set., 2010 
brotos secundários. Na obtenção da massa seca, os brotos e as raízes secundários permaneceram ligados aos brotos primários e, assim, fizeram parte da observação.

Para a obtenção dos valores de massa seca da parte aérea e do sistema radicial, as brotações e as raízes foram separadas da estaca e previamente secas ao ar. Em seguida, ambos os materiais levados à estufa, a aproximadamente $60^{\circ} \mathrm{C}$, até atingirem peso constante, obtido por meio de balança de precisão.

Os dados foram analisados estatisticamente por meio dos softwares SPSS 8.0 e Excel. As diferenças entre as médias foram comparadas pelo teste de Tukey a $5 \%$ de probabilidade de erro.

\section{RESULTADOS E DISCUSSÕES}

Os resultados apresentados a seguir foram obtidos de trinta repetições. No entanto, foram analisados os dados apenas das estacas vivas em cada ângulo de plantio, exceto quando se analisou a sobrevivência destas.

Os valores mínimos, médios e máximos, o desvio-padrão e o coeficiente de variação, referentes ao diâmetro da base das estacas de Phyllanthus sellowianus (Klotzsch) Müll. Arg., plantadas em diferentes ângulos são apresentados na Tabela 1. Pode-se observar que as estacas utilizadas apresentaram diâmetros com valores médios e de dispersão semelhantes indicando a distribuição randômica das estacas para os três tratamentos.

$\mathrm{O}$ ângulo de plantio não influenciou na sobrevivência das estacas (Figura 1). A

TABELA 1: Diâmetro da base das estacas de Phyllanthus sellowianus plantadas em diferentes ângulos.

TABLE 1: Diameter of the base of cuttings of Phyllanthus sellowianus planted at different angles.

\begin{tabular}{c|c|c|c|c|c}
\hline \multirow{2}{*}{$\begin{array}{c}\text { Ângulo } \\
\text { de plantio }\end{array}$} & \multicolumn{5}{|c}{ Diâmetro das estacas (mm) } \\
\cline { 2 - 6 } & Mín* & Max & Méd & DP & CV \\
\hline $10^{\circ}$ & 10,0 & 29,0 & 17,6 & 5,6 & 31,82 \\
$30^{\circ}$ & 13,0 & 26,0 & 17,9 & 3,5 & 19,55 \\
$90^{\circ}$ & 13,5 & 29,0 & 20,0 & 3,9 & 19,50 \\
\hline
\end{tabular}

Em que: * Mín = mínimo; Máx = máximo; Méd = média; $\mathrm{CV}=$ coeficiente de variação (\%); $\mathrm{DP}=$ Desvio padrão.

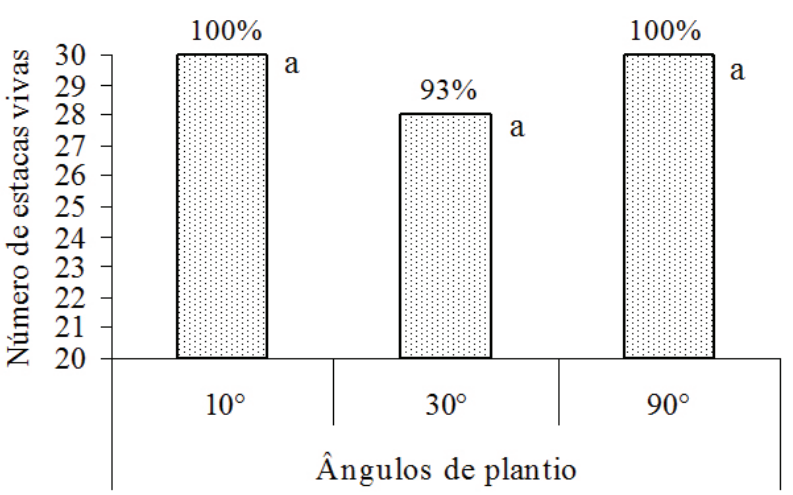

FIGURA 1: Número de estacas vivas de Phyllanthus sellowianus e a equivalente porcentagem de sobrevivência de estacas nos três ângulos de plantio aos 90 dias. Valores seguidos de mesma letra, entre as barras, não diferem entre si pelo teste de Tukey em nível de 5\% de probabilidade de erro.

FIGURE 1: Number of live cuttings of Phyllanthus sellowianus and equivalent survival percentage of cuttings at the three angles of planting at 90 days. Values followed by same letter, between the bars, do not differ by Tukey test at 5\% level of probability of error.

sobrevivência variou de 28 estacas vivas quando estas foram plantadas em ângulo de $30^{\circ}$ a 30 estacas vivas quando plantadas em ângulos de $10^{\circ}$ e $90^{\circ}$, o que corresponde em porcentagem a 93\% e 100\% de sobrevivência, respectivamente (Figura 1). Podese considerar que os valores da sobrevivência são elevados em todos os ângulos de plantio, quando comparados aos valores encontrados por Vargas (2007), Sutili (2004) e Sutili (2007), ao analisarem a sobrevivência da mesma espécie em seus experimentos.

No entanto, somente informações referentes à sobrevivência das estacas não permite julgá-las quanto à influência ou não do ângulo de plantio sobre o desenvolvimento da espécie. Assim, os valores estatísticos correspondentes ao número, ao diâmetro, à soma de comprimento e à massa seca dos brotos de estacas plantadas nos diferentes ângulos são apresentados na Tabela 2. Os valores relativos ao número e ao diâmetro de brotos são semelhantes, ou seja, não apresentam diferença significativa entre os ângulos de plantio. Vargas (2007) estudando o desenvolvimento da parte aérea de Phyllanthus sellowianus (Klotzsch) Müll. Arg. 
TABELA 2: Número, diâmetro $(\mathrm{mm})$, soma do comprimento $(\mathrm{cm})$ e massa seca $(\mathrm{g})$ dos brotos primários para estacas plantadas em diferentes ângulos.

TABLE 2: Number, diameter $(\mathrm{mm})$, sum of the length $(\mathrm{cm})$ and dry mass $(\mathrm{g})$ of primary shoots for cuttings planted at different angles.

\begin{tabular}{|c|c|c|c|c|c|c|c|c|c|c|c|c|}
\hline \multirow{3}{*}{ Var } & \multicolumn{12}{|c|}{ Ângulos de plantio } \\
\hline & \multicolumn{4}{|c|}{$10^{\circ}$} & \multicolumn{4}{|c|}{$30^{\circ}$} & \multicolumn{4}{|c|}{$90^{\circ}$} \\
\hline & Mín & Máx & Méd $^{2}$ & $\mathrm{CV}$ & Mín & Máx & Méd & $\mathrm{CV}$ & Mín & Máx & Méd & $\mathrm{CV}$ \\
\hline NB & 1,0 & 8,0 & $3,3 \mathrm{a}$ & 45,6 & 1,0 & 6,0 & $2,6 \mathrm{a}$ & 55,8 & 1,0 & 5,0 & $3,2 \mathrm{a}$ & 36,3 \\
\hline DB & 2,5 & 5,8 & $3,5 \mathrm{a}$ & 20,0 & 2,2 & 7,0 & $3,7 \mathrm{a}$ & 39,7 & 2,7 & 6,0 & $4,0 \mathrm{a}$ & 21,8 \\
\hline $\mathrm{SC}$ & 15,6 & 166,1 & $85,1 \mathrm{ab}$ & 45,9 & 38,2 & 135,5 & $72,8 b$ & 43,6 & 45,5 & 181,2 & $98,7 \mathrm{a}$ & 35,7 \\
\hline MS & 0,02 & 6,98 & $3,19 b$ & 53,6 & 0,52 & 6,98 & $2,90 \mathrm{~b}$ & 58,6 & 1,49 & 9,75 & $4,39 \mathrm{a}$ & 47,8 \\
\hline
\end{tabular}

Em que: Var = variáveis; $\mathrm{NB}=$ número de brotos; $\mathrm{DB}=$ diâmetro dos brotos $(\mathrm{mm}) ; \mathrm{SC}=$ soma do comprimento dos brotos $(\mathrm{cm}) ; \mathrm{MS}=$ massa seca $(\mathrm{g})$ dos brotos; Mín = mínimo; Máx = máximo; Méd = média; $\mathrm{CV}=$ coeficiente de variação (\%). ${ }^{2}$ Médias seguidas de mesma letra, na mesma linha, não diferem entre si pelo Teste de Tukey em nível de $5 \%$ de probabilidade de erro.

ao longo do tempo, em um canteiro experimentalpadrão (DURLO e SUTILI, 2005), obteve valores semelhantes para tais variáveis quando analisadas aos três meses após o plantio.

Ao se observar a soma do comprimento e a massa seca dos brotos, verifica-se que há diferenças significativas entre estacas plantadas nos diferentes ângulos (Tabela 2).

Asoma do comprimento de brotos das estacas de Phyllanthus sellowianus (Klotzsch) Müll. Arg. apresentou comportamento diferenciado em função do ângulo de plantio, ou seja, estacas plantadas em ângulo de $90^{\circ}$ diferiram significativamente daquelas plantadas em ângulo de $30^{\circ}$, mas não diferiram daquelas plantadas em ângulo de $10^{\circ}$. As últimas, no entanto, são semelhantes às plantadas em ângulo de $30^{\circ}$.

As médias da soma do comprimento dos brotos variaram de $72,8 \mathrm{~cm}\left(30^{\circ}\right)$ a $98,7 \mathrm{~cm}\left(90^{\circ}\right)$ aos 90 dias após o plantio (Tabela 2). Após 90 dias, Sutili (2007) encontrou resultados semelhantes para estacas de Phyllanthus sellowianus (Klotzsch) Müll. Arg. mantidas em água e testadas em diferentes épocas do ano. Assim, no outono (abril-junho), encontrou uma soma de comprimento de brotos por estaca acima de $25 \mathrm{~cm}$; no inverno (julho-setembro), abaixo de $25 \mathrm{~cm}$; na primavera (outubro-dezembro), próximo de $100 \mathrm{~cm}$; e no verão (janeiro-março) próximo de $50 \mathrm{~cm}$.

Outra variável que se mostrou influenciada pelo ângulo de plantio foi a massa seca dos brotos, visto que estacas plantadas em ângulo de $90^{\circ}$ apresentaram valores superiores e estatisticamente diferentes quando comparadas com estacas plantadas em ângulos de 10 e $30^{\circ}$ (Tabela 2).

Em estacas plantadas em ângulos de 10 e $30^{\circ}$, a massa seca dos brotos não passou de $7 \mathrm{~g}$, enquanto naquelas plantadas em ângulo de $90^{\circ}$ esta atingiu até $10 \mathrm{~g}$. Na Figura 2, vê-se que a maioria das estacas plantadas em ângulos de 10 e $30^{\circ}$ apresentou massa seca entre 1 e 4 g. Fica visível ainda que a distribuição da massa seca dos brotos foi mais ampla quando as estacas foram plantada em ângulo de $90^{\circ}$, embora quase $1 / 3$ das estacas tenham apresentado massa seca em torno de $3 \mathrm{~g}$.

Assim como para os brotos também para o enraizamento, foram calculados os valores mínimos, médios e máximos, o desvio-padrão e o coeficiente de variação referentes ao número e à soma do comprimento das raízes primárias, ao comprimento e ao diâmetro da raiz mais longa e à massa seca das raízes de estacas plantadas nos diferentes ângulos (Tabela 3). Ao se observar a comparação entre os valores médios das variáveis da Tabela 3 , verificase que há diferenças significativas entre as variáveis analisadas.

Exceto para o diâmetro de raízes, em todas as variáveis analisadas, vê-se que as estacas plantadas em ângulo de $90^{\circ}$ apresentaram valores mais altos que os valores de estacas plantadas nos demais ângulos (Tabela 3). As diferenças dos valores médios da soma do comprimento de raízes e do número de raízes são estatisticamente significativas (Figuras 3 e 4) e são semelhantes 

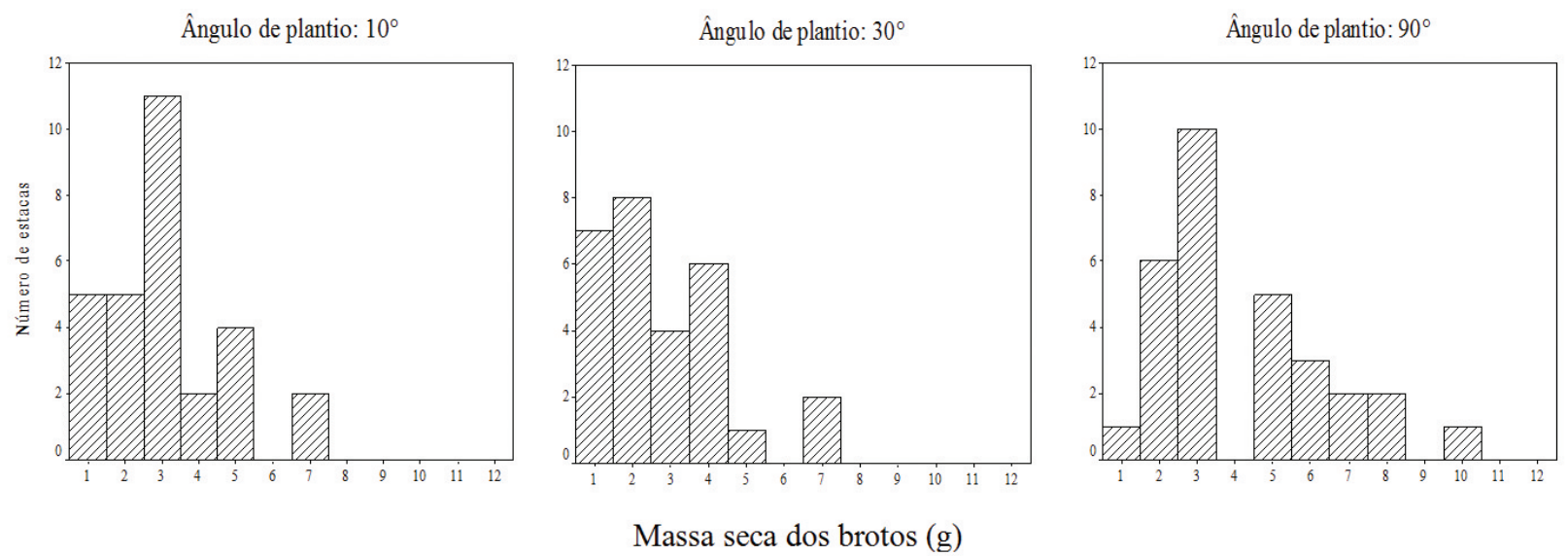

FIGURA 2: Distribuição da massa seca dos brotos (g) de Phyllanthus sellowianus nos diferentes ângulos de plantio.

FIGURE 2: Distribution of the dry mass of shoots (g) of Phyllanthus sellowianus at the different angles of planting.

TABELA 3: Número, diâmetro ( $\mathrm{mm})$, soma do comprimento $(\mathrm{cm})$ e a massa seca $(\mathrm{g})$ das raízes por estaca plantada em diferentes ângulos.

TABLE 3: Number, diameter $(\mathrm{mm})$, sum of the length $(\mathrm{cm})$ and dry mass $(\mathrm{g})$ of roots per cutting planted at different angles.

\begin{tabular}{|c|c|c|c|c|c|c|c|c|c|c|c|c|}
\hline \multirow{3}{*}{ Var } & \multicolumn{12}{|c|}{ Ângulo de plantio } \\
\hline & \multicolumn{4}{|c|}{$10^{\circ}$} & \multicolumn{4}{|c|}{$30^{\circ}$} & \multicolumn{4}{|c|}{$90^{\circ}$} \\
\hline & Mín & Máx & Méd $^{1}$ & $\mathrm{CV}$ & Mín & Máx & Méd & $\mathrm{CV}$ & Mín & Máx & Méd & $\mathrm{CV}$ \\
\hline NR & 10,0 & 69,0 & $40,2 b$ & 42,0 & 15,0 & 98,0 & $50,6 \mathrm{~b}$ & 35,4 & 30,0 & 130,0 & $63,1 \mathrm{a}$ & 35,3 \\
\hline DR & 1,0 & 3,0 & $1,7 \mathrm{a}$ & 35,3 & 1,0 & 3,0 & $1,4 b$ & 28,6 & 1,0 & 2,5 & $1,4 b$ & 28,6 \\
\hline $\mathrm{SC}$ & 74,9 & 1171,8 & $514,7 \mathrm{~b}$ & 48,9 & 215,8 & 1284,9 & $619,0 \mathrm{~b}$ & 43,8 & 250,5 & 1928,9 & $898,6 a$ & 46,4 \\
\hline MS & 0,4 & 1,9 & $1,0 \mathrm{ab}$ & 40,0 & 0,4 & 1,5 & $0,9 b$ & 33,3 & 0,5 & 2,7 & $1,2 \mathrm{a}$ & 41,7 \\
\hline
\end{tabular}

Em que: Var = variáveis; $\mathrm{NR}=$ número de raízes; $\mathrm{DR}=$ diâmetro da raiz mais longa $(\mathrm{mm}) ; \mathrm{SC}=$ soma do comprimento das raízes $(\mathrm{cm}) ; \mathrm{MS}=$ massa seca $(\mathrm{g})$ das raízes; Mín = mínimo; Máx = máximo; Méd = média; $\mathrm{CV}=$ coeficiente de variação (\%). ${ }^{1}$ Médias seguidas de mesma letra, na mesma linha, não diferem entre si pelo Teste de Tukey em nível de $5 \%$ de probabilidade de erro.

aos valores encontrados por Sutili (2007) e Vargas (2007) respectivamente.

$\mathrm{Na}$ Figura 5, vê-se que as médias do comprimento da raiz mais longa se assemelham, mas os extremos se diferenciam. Por exemplo, no ângulo de $10^{\circ}$, observou-se que o comprimento da raiz mais longa apresentou um valor mínimo em torno de $8,0 \mathrm{~cm}$, enquanto para os demais ângulos o valor mínimo ficou em torno de $19,0 \mathrm{~cm}$. No entanto, para os valores máximos o ângulo que apresentou menor valor foi o de $30^{\circ}$, em torno de $60 \mathrm{~cm}$, ao passo que os ângulos de $10^{\circ}$ e $90^{\circ}$ apresentaram valores entre 65 e $70 \mathrm{~cm}$ respectivamente. $\mathrm{O}$ teste de Tukey em nível de 5\% de probabilidade de erro não mostrou diferença significativa entre as médias dessa variável.

Quanto ao diâmetro basal da raiz mais longa, foi possível verificar que, nas estacas plantadas no ângulo de $10^{\circ}$, há um maior número de raízes mais grossas (Figura 6), fato esse que talvez possa explicar a diferença significativa determinada pelo teste de média (Tabela 3).

No que diz respeito à massa seca das raízes (Figura 7), verificou-se que estacas plantadas em ângulo de $90^{\circ}$ apresentaram valores significativamente maiores do que no ângulo de $30^{\circ}$, porém não diferente do ângulo de $10^{\circ}$ (Tabela $3 \mathrm{e}$ Figura 7). Esse resultado é reflexo do maior número 

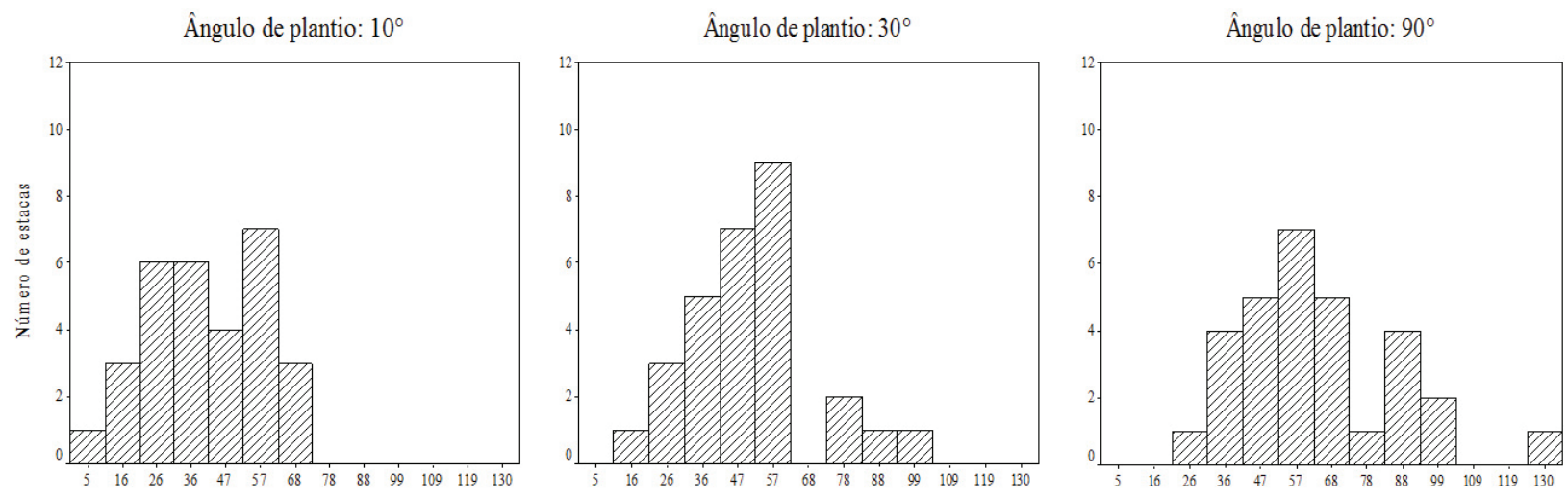

Número de raízes por estaca

FIGURA 3: Frequência do número de raízes de Phyllanthus sellowianus nos diferentes ângulos de plantio. FIGURE 3: Frequency of the number of roots of Phyllanthus sellowianus at the different angles of planting.

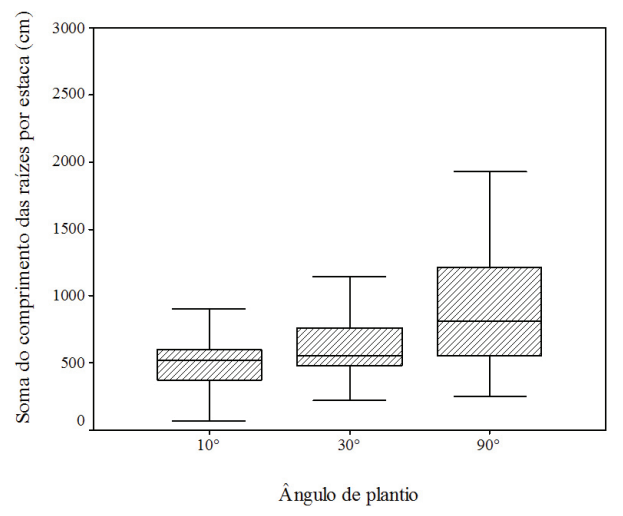

FIGURA 4: Soma do comprimento de raízes (cm) de Phyllanthus sellowianus nos diferentes ângulos de plantio.

FIGURE 4: Sum of the length of roots $(\mathrm{cm})$ of Phyllanthus sellowianus at the different angles of planting.

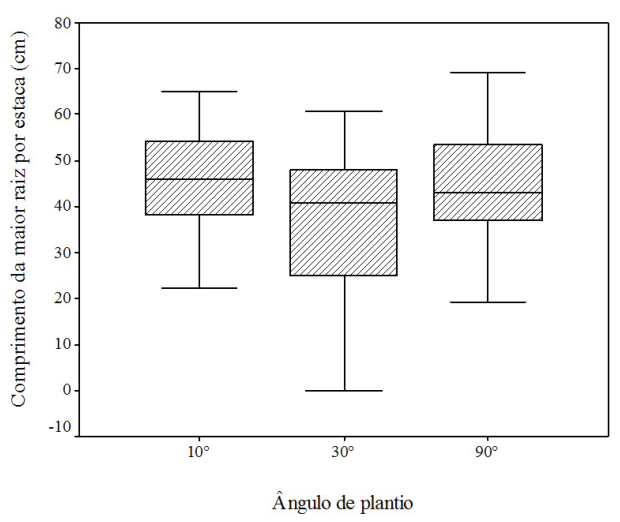

FIGURA 5: Comprimento da raiz mais longa (cm) de Phyllanthus sellowianus nos diferentes ângulos de plantio.

FIGURE 5: Length of the longest root $(\mathrm{cm})$ of Phyllanthus sellowianus at the different angles of planting.
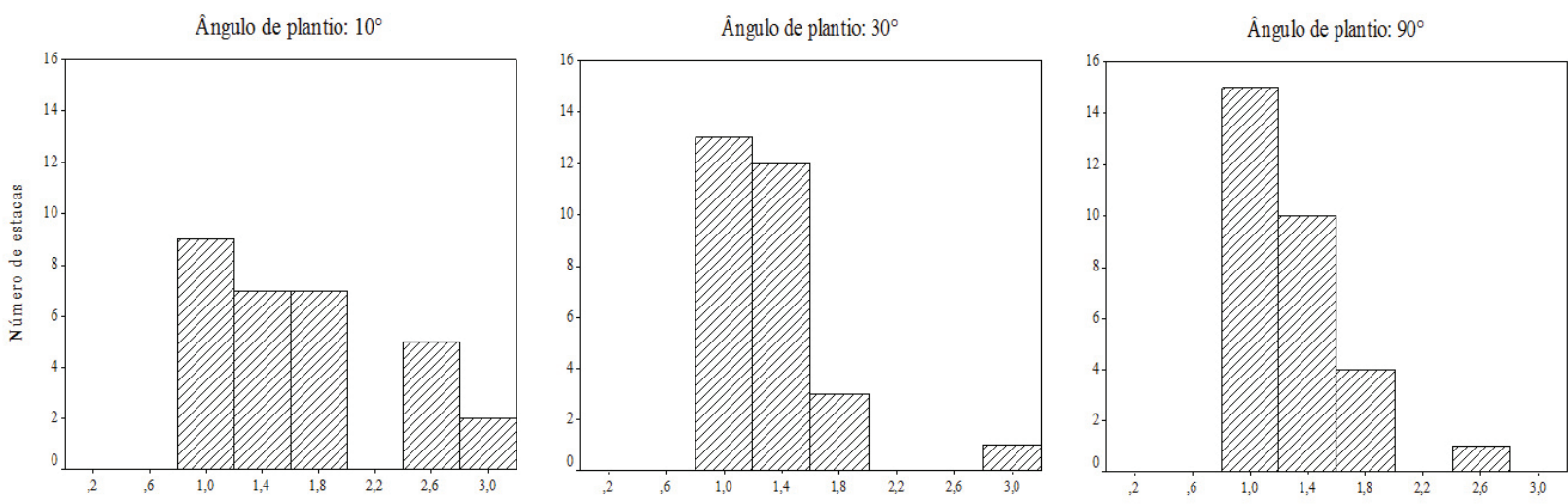

Diâmetro basal da raiz mais longa (mm)

FIGURA 6: Distribuição do diâmetro basal da raiz mais longa ( $\mathrm{mm}$ ) de Phyllanthus sellowianus nos diferentes ângulos de plantio.

FIGURE 6: Distribution of basal diameter of the longest root (mm) of Phyllanthus sellowianus at the different angles of planting.

Ci. Fl., v. 20, n. 3, jul.-set., 2010 


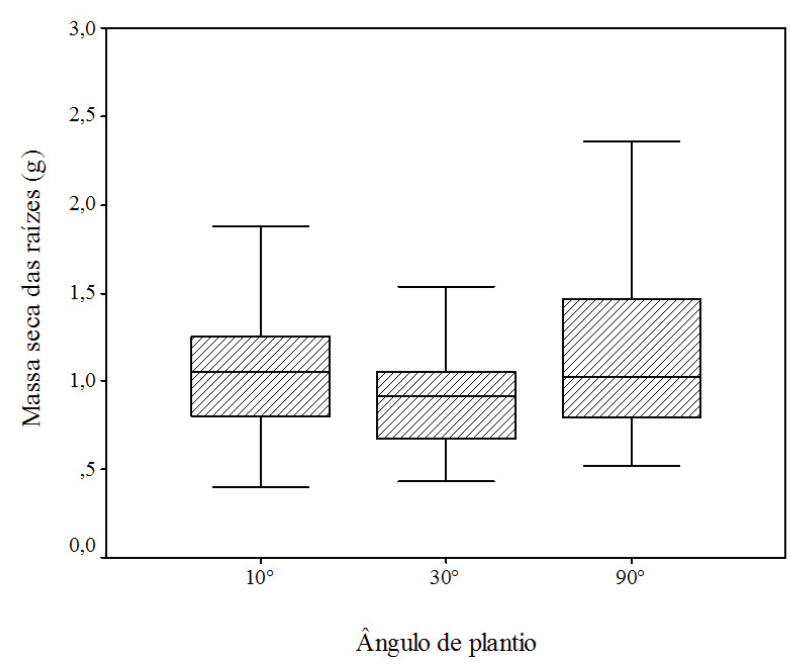

FIGURA 7: Massa seca das raízes (g) de Phyllanthus sellowianus nos diferentes ângulos de plantio.

FIGURE 7: Dry mass of roots (g) of Phyllanthus sellowianus at the different angles of planting.

e elevada soma de comprimento de raízes, também obtidos para esse ângulo de plantio.

O tratamento que produziu a menor massa seca de raízes foi o plantio em ângulo de $30^{\circ}$, embora os valores encontrados para este não tenham sido estatisticamente diferentes dos verificados para o ângulo de plantio de $10^{\circ}$.

Uma variável que não foi quantificada para este trabalho, mas que teve observações empíricas no decorrer das observações de campo foi a distribuição das raízes ao longo da porção enterrada da estaca. Foi possível observar que, nos ângulos de $10^{\circ}$ e $30^{\circ}$, mesmo tendo apresentado menor número e soma de comprimento de raízes, estas, no entanto, se encontravam melhor distribuídas ao longo de toda a porção enterrada. Estacas na posição de $90^{\circ}$ geralmente possuíam as raízes concentradas na base, ou apenas, nos $10 \mathrm{~cm}$ inferiores da estaca.

\section{CONCLUSÕES}

O ângulo de plantio não exerce influência sobre a sobrevivência e o diâmetro dos brotos primários, porém influencia sobre a massa seca dos brotos. A influência do ângulo de plantio também pode ser comprovada para o número e o diâmetro das raízes primárias bem como para a massa seca das raízes.

Com base nos resultados obtidos, presume- se que Phyllanthus sellowianus (Klotzsch) Müll. Arg. pode ser utilizada em diversas práticas biotécnicas que exijam o plantio da vegetação na posição vertical ou ainda na posição horizontal. Assim, a espécie apresenta potencial para ser usada em cilindros vivos, em que os feixes de estacas são posicionados quase horizontalmente no terreno ou, ainda, em banquetas onde o plantio geralmente é feito em pequenos ângulos entre 10 e $20^{\circ}$. Entretanto, uma afirmação categórica a esse respeito só pode ser feita com a avaliação de experimentos adicionais.

Da mesma maneira, experimentos posteriores poderão vir a confirmar a viabilidade do uso de Phyllanthus sellowianus (Klotzsch) Müll. Arg. em esteiras vivas onde os ramos são implantados em ângulos entre $30^{\circ}$ a $45^{\circ}$. Embora o ângulo de $30^{\circ}$, neste experimento, tenha desfavorecido a brotação e o enraizamento, a grande quantidade de material exigida por essa técnica pode compensar tal desvantagem.

\section{REFERÊNCIAS BIBLIOGRÁFICAS}

AWAD, M.; CASTRO, P. R. C. Introdução a Fisiologia Vegetal. 2. ed. São Paulo: Nobel, 1997, 177 p.

CABRERA, A. L. et al. Flora de la Província de Buenos Aires: Oxalidáceas a Umbelíferas. Parte IV. Buenos Aires: Instituto Nacional de Tecnologia Agropecuário, 1965.

DURLO, M. A. Biotécnicas no manejo de cursos de água. Ciencia e Ambiente, Santa Maria, n. 21, p. 81-90, 2000.

DURLO, M. A.; SUTILI, F. J. Bioengenharia: Manejo de Cursos de Água. Porto Alegre: EST, 2005. 189 p.

FACHINELLO, J. C. et al. Propagação de plantas frutíferas de clima temperado. Pelotas: UFPEL, 1994. 179 p.

FLORINETH, F. Pflanzen statt Beton. Handbuch zur Ingenieurbiologie und Vegetationstechnik. Patzer Verlag Berlin - Hannover, ISBN 3-87617107-5, 282 Seiten. 2004.

LOMBARDO, A. Flora arbórea y arborescente del Uruguay. 2. ed. Montevideo, 1964, 218 p. MORENO, J. A. Clima do Rio Grande do Sul. Porto Alegre: Secretaria da Agricultura, 1961.

RAVEN, P. H. et al. Biologia Vegetal. Rio de Janeiro: Guanabara Koogan, 1996, 728 p.

SCHIECHTL, H. M. Bioingegneria forestale: Basi - materiali da construzione vivi - metodi. Castaldi Feltre, 1973. 
SCHIECHTL, H. M.; STERN, R. Handbuch für naturnahen Erdbau: Eine Einleitung für ingenieurbiologische Bauweisen. Wien: Österreichischer Agrarverlag, Druck und Verlagsgesellschaft m.b.H., 1992.

SOUZA, V. C.; LORENZI, H. Botânica sistemática: guia ilustrado para identificação das famílias de Angiospermas dicotiledôneas da flora brasileira, baseado em APG II. Nova Odessa: Instituto Plantarum, 2005. $640 \mathrm{p}$.

SUTILI, F. J. Manejo biotécnico do arroio Guarda-Mor: princípios, processos e práticas. 2004. 114 f. Dissertação (Mestrado em Engenharia Florestal) - Universidade Federal de Santa Maria,
Santa Maria, 2007.

SUTILI, F. J. Bioengenharia de solos no âmbito fluvial do sul do Brasil. 2007. 95 p. Tese de Doutorado (Instituto de Bioengenharia de Solos e Planejamento da Paisagem) - Universidade Federal de Viena, Viena, 2007.

TAIZ, L.; ZEIGER, E. Plant Physiology. California: Reedwood. 2007. 623 p.

VARGAS, C. O. Características biotécnicas de Phyllanthus sellowianus (Klotzsch) Müll. Arg., Salix x rubens Schanck e Sebastiania schottiana (Müll. Arg) Müll. Arg. 2007. 84 f. Dissertação (Mestrado em Engenharia Florestal) - Universidade Federal de Santa Maria, Santa Maria, 2007. 